\title{
High Expression Vectors for a Zygosaccharomyces rouxii Host
}

\author{
Toshiaki Imura, Ikuyo Utatsu and Akio Toh-E* \\ Department of Fermentation Technology. Hiroshima University, \\ Shitami, Saijo, Higashihiroshima 724, Japan \\ Received October 24, 1988
}

\begin{abstract}
We evaluated the expression of three yeast genes in Zygosaccharomyces rouxii using lac $Z$ as a reporter gene; they were the glyceraldehyde-3-phosphate dehydrogenase gene of $Z$. rouxii $(G A P-Z r)$, that of $S$. cerevisiae $(G A P-S c)$ and the PHO5 gene of $S$. cerevisiae. The GAP-Sc promoter showed high expression in the $Z$. rouxii host as well as in the $S$. cerevisiae host. The $G A P-Z r$ promoter showed a comparable level of expression as the $G A P-S c$ both in the $S$. cerevisiae host and the $Z$. rouxii host. The transcription initiation site of the $G A P-Z r$ promoter in the heterologous host seems to be the same as that in the homologous host. The $P H O 5$ promoter showed constitutive expression, as efficient as in the case of the $G A P$ - $Z$ r promoter, in the $Z$. rouxii host. All the promoters mentioned above can be used as sources of a high expression vector in the $Z$. rouxii host.
\end{abstract}

Zygosaccharomyces rouxii is one of the yeasts which are used in the field of fermentation industry. Two plasmids, pSR1 and pSB3, have been found in $Z$. rouxi $i^{1,2)}$ and used for constructing various composite plasmids. A transformation method involving a leu ${ }^{-}$strain of $Z$. rouxii, ME3, has been developed. ${ }^{2 a)} \mathrm{By}$ using these plasmid vectors and a host strain, a heterologous gene can be introduced into $Z$. rouxii. To express a foreign gene in $Z$. rouxii efficiently, however, it is necessary to place the gene under the control of an appropriate promoter which functions in $Z$. rouxii. Development of expression vectors and $Z$. rouxii hosts will be usefull for improving $Z$. rouxii strains which are in practical use.

In the previous study, we cloned and sequenced one of the structural genes for glyceraldehyde-3-phosphate dehydrogenase $(G A P)$ from $Z$. rouxii. ${ }^{3)}$ Since the $G A P$ gene is known to be as one of the highly expressed genes in $S$. cerevisiae ${ }^{4)}$ and since the condon usage of deduced amino acid sequence of the $G A P$ gene of $Z$. rouxii $(G A P-Z r)$ is strongly biased, this gene is supposed to be a highly expressed gene. In this communication, we present evidence showing that the promoter of the $G A P-Z r$ gene shows as efficient expression as $G A P-S c$ in $Z$. rouxil, as well as in $S$. cerevisiae. The GAP-SC and PHOS promoters of $S$. cerevisiae also show high expression in $Z$. rouxii.

\section{Materials and Methods}

Organisms. The yeasts, bacterial strains and plasmids used in this study are listed in Table I. Z. rouxii ME3 harbors plasmid pSR1. ME3 [pSB3] contains plasmid pSB3 in addition to pSR l, and both plasmids are maintained stably in it." The leu phenotype of ME3 can be complemented with the $L E U 2$ gene of $S$. cerevisiae.

Media. For yeasts: YEPD contained $2 \%$ Polypepton (Daigo Eiyo), $1 \%$ yeast extract (Oriental Yeast) and 2\% glucose. SD contained $0.67 \%$ yeast nitrogen base without amino acids (DIFCO) and $2 \%$ glucose. For cultivation of Z. rouxii, $5 \% \mathrm{NaCl}$ was added to YEPD and SD. Leucine $(20 \mu \mathrm{g} / \mathrm{ml})$ was added as necessary. For E. coli: nutrient broth and L-broth were prepared as described. ${ }^{6)}$ McConkey agar (Daigo Eiyo) was used for selecting $\mathrm{Lac}^{+}$ E. coli. Ampicillin $(50 \mu \mathrm{g} / \mathrm{ml})$ or tetracycline $(10 \mu \mathrm{g} / \mathrm{ml})$ was added as appropriate.

Techniques for nucleic acids. Plasmid isolation, gel electrophoresis, construction of plasmids in vitro and extraction of RNA from yeast were carried out as described. ${ }^{7}$ " DNA sequencing was performed by the Maxam-Gilbert 
Table I. List of Strains and Plasmids

\begin{tabular}{|c|c|c|}
\hline Organism & Genotype or character & Reference or source \\
\hline \multicolumn{3}{|c|}{ Zygosaccharomyces rouxii } \\
\hline ME3 & $\mathrm{Leu}^{-}$ & 5) \\
\hline ME3 (pSB3) & $\mathrm{Leu}^{-}$ & 5) \\
\hline \multicolumn{3}{|c|}{ Saccharomyces cerevisiae } \\
\hline $\mathrm{K} 12-2 \mathrm{~A}\left(\mathrm{cir}^{0}\right)$ & $M A T_{\alpha}$ leu 2 ura 3 & Our stock \\
\hline \multicolumn{3}{|l|}{ Escherichia coli } \\
\hline JA221 & $\mathrm{F}^{-}$leuB6 trp $\triangle E 5$ rec A hsdR lac $Y$ & 16) \\
\hline MC1066 & $\begin{array}{l}\mathrm{F}^{-} \text {leuB } \operatorname{trp} C 9830 \Delta(\text { lac }) X 74 \text { str } A \\
\text { pyrF74:: } \mathrm{Tn} 5\left(\mathrm{Km}^{\mathrm{r}}\right)\end{array}$ & 17) \\
\hline \multicolumn{3}{|l|}{ Plasmids } \\
\hline YIp32 & LEU2 $\mathrm{Ap}^{\mathrm{r}}$ & 18) \\
\hline YIp33 & LEU2 $\mathrm{Ap}^{\mathrm{r}}$ & 18) \\
\hline pMC1871 & lac' $Z \mathrm{Ap}^{\mathrm{r}}$ & 17) \\
\hline $\mathrm{pMCl} 415$ & lac'Z TRPI ARSI Ap' & $\begin{array}{l}\text { Arias-Martinez and } \\
\text { Casadaban }\end{array}$ \\
\hline pAT87 & PHO5 $\mathrm{Tc}^{\mathrm{r}}$ & Our stock \\
\hline $\mathrm{pGCl}$ & $G A P-S c-l a c Z A^{T}$ & T. Oshima \\
\hline pGAP1-Zr & $G A P-Z r \mathrm{Ap}^{r}$ & 3) \\
\hline pSR1 & Cryptic & 1) \\
\hline pSB3 & Cryptic & 2) \\
\hline
\end{tabular}

method. ${ }^{81}$ The primer extension reaction was carried out as described by Hahn et al. ${ }^{9}$

Determination of $\beta$-galactosidase activity. The assay for $\beta$-galactosidase activity was that as described by Miller ${ }^{6)}$ with partial modification. A transformant to be tested was grown at $28 \mathrm{C}$ in the selective medium with shaking. An appropriate volume of the culture was taken at the mid-log phase, a part of which was used for measuring $O D_{660 \mathrm{~nm}}$ and a part for computing the fraction of cells retaining the plasmid. Cells were harvested from a given amount of the culture, washed with $1 \mathrm{ml}$ of water and then resuspended in $1 \mathrm{ml}$ of Z-buffer ( $1 \mathrm{mM} \mathrm{MgSO}_{4}, 0.06 \mathrm{M} \mathrm{Na}_{2} \mathrm{HPO}_{4}, 0.04 \mathrm{M}$ $\mathrm{NaH}_{2} \mathrm{PO}_{4}, 0.01 \mathrm{M} \mathrm{KCl}, 0.05 \mathrm{M} \quad \beta$-mercaptoethanol, $\mathrm{pH}$ 7.0). After adding $50 \mu \mathrm{l}$ of chloroform and $20 \mu \mathrm{1}$ of $0.1 \%$ SDS, the mixture was vortexed and then incubated at $28^{\circ} \mathrm{C}$ $5 \mathrm{~min}$. The reaction was started by adding $0.2 \mathrm{ml} o-$ nitrophenyl- $\beta$-D-galactoside $(4 \mathrm{mg} / \mathrm{ml})$ to the above mixture. The incubation was continued until a pale yellow color developed. The reaction was stopped by adding $0.5 \mathrm{ml}$ of $\mathrm{I} \mathrm{M} \mathrm{Na} \mathrm{CO}_{3}$. After removing the chloroform, the cells were spun down and the absorbance at $420 \mathrm{~nm}$ of the resulting supernatant was determined. The enzyme unit was defined as follows:

$$
\text { units }=1000 \times \mathrm{OD}_{420 \mathrm{~nm}} /\left(\mathrm{OD}_{660 \mathrm{~nm}} \times t \times y\right)
$$

where $t$ is the incubation time (minutes) and $v$ is the culture volume $(\mathrm{ml})$ for the enzyme assay.

Stability of the plasmids. A portion of a culture, taken as described above, was diluted appropriately and then spread on YEPD or YEPD containing $5 \% \mathrm{NaCl}$, depending on the host. After $3 \sim 4$ days incubation, colonies were replica-plated onto plates containing a synthetic medium without leucine to determine the number of $\mathrm{Leu}^{+}$ colonies.

\section{Results}

Construction of plasmids containing the lacZ fusion gene

To determine the extent of expression of the $G A P-Z r$ promoter, a $G A P-Z r-l a c Z$ fusion gene was constructed. The $700 \mathrm{bp}$ Pst $\mathrm{I}-\mathrm{Hpa \textrm {I }}$ fragment containing the $G A P-Z r$ promoter (from pGAPl-Zr), the $3.2 \mathrm{~kb}$ SmaI-Sal I fragment carrying the lac $Z$ gene (from pMC1871) and the $5.2 \mathrm{~kb}$ Sal I-Pst I fragment carrying the LEU2 gene (from YIp33) were ligated to obtain pTI46 (not shown). pTI46 was used for the construction of pTI48, pTI49, pTI51 and pTI52 (Fig. 1). The PHO5-lacZ fusion gene was constructed as shown in Fig. 2. First, pAT190 was constructed by ligating the $2 \mathrm{~kb}$ Pst I-BamHI fragment carrying the PHO5 gene (from pAT87), the $6 \mathrm{~kb}$ Pst I-SalI fragment carrying the lac $Z$ gene (from pMC1415) 


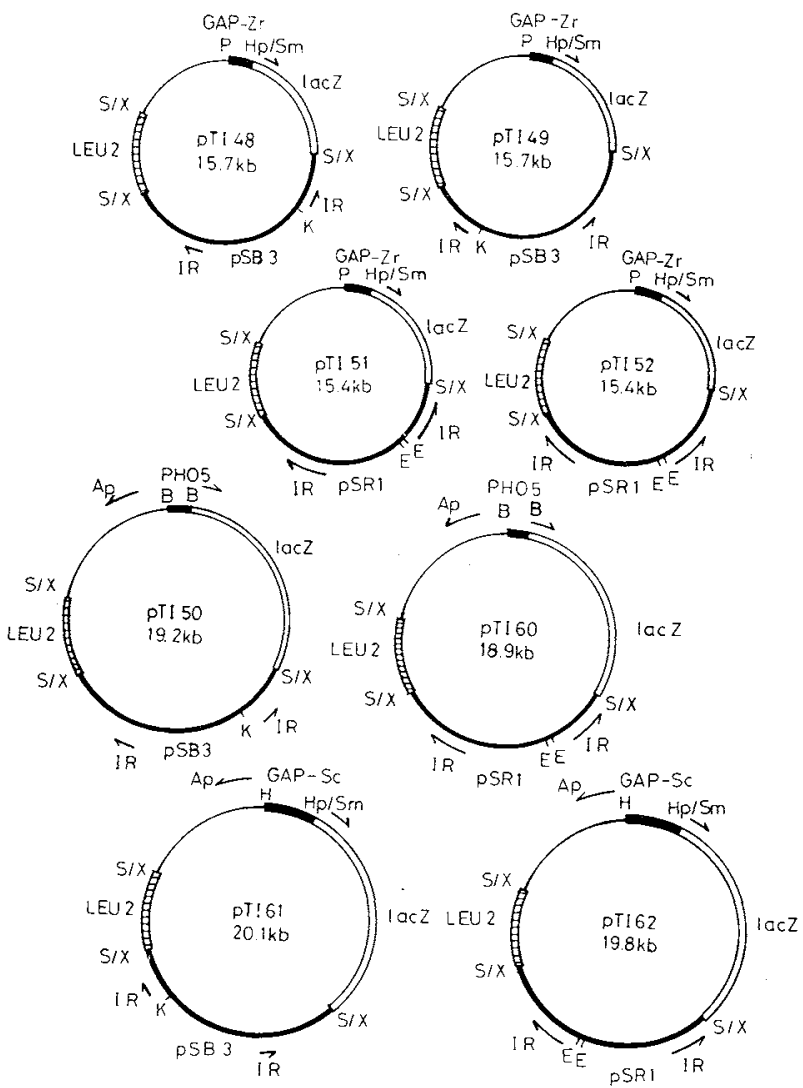

Fig. 1. Structures of Plasmids Containing a lacZ-fusion Gene.

Filled boxes indicate the yeast promoters and open boxes the lac gene. The hatched boxes indicate the LEU2 gene. The length of lac DNA used varied; in pTI48, pTI49, pTI5I and pTI52, the lac DNA contains only lacZ. In the rest of the plasmids, the lac DNA contains lac $Y$ and lac $A$ in addition to lacZ. Both $G A P-Z r$ and $G A P-$ $S c$ contain a $H p a I$ site, however, the position of the $H p a$ I site in $G A P-Z r$ is different from that in $G A P-S c$. Therefore, the length of the N-terminal amino acids fused to $l a c Z$ is different in $G A P-Z r-l a c$ and $G A P-S c-$ lac. An arrow shown on the lac $Z$ gene indicates the direction of the transcription. Arrows on the plasmid segment (thick line) indicate the position of IR. Thin lines indicate the pBR322 sequences. An arrow, Ap, indicates the orientation of the Ap gene. E, EcoRI; K, KpnI; Hp/Sm, HpaI/SmaI; S/X, Sal I/Xhol; P, Pst I.

and the $4 \mathrm{~kb}$ Sal I-BamHI fragment from pBR322. In this plasmid, the PHO5 and lac $Z$ genes orientated in the same direction. pAT190 was linearized with $K p n I$, which cuts inside the coding region of the PHO5 gene, and digested partially with Bal-31 nuclease and then with SmaI. The resulting DNA mixture was treated with T4-DNA ligase and then used as donor DNA for the transformation of a $\mathrm{lac}^{-}$E. coli host (MC1066) from lac ${ }^{-}$to $\mathrm{lac}^{+}$. The transformation mixture was spread on a plate of McConkey agar containing ampicillin. Red colonies were isolated as transformants containing the PHO5-lacZ fusion gene. The nucleotide sequence at the junction between the PHO5 and lacZ genes was determined by the Maxam-Gilbert method ${ }^{8)}$ to confirm the in-frame joining of the PHOS and lacZ genes (Fig. 3). One of the isolates, pAT335, was subjected to further study. The HindIII-Sal I fragment carrying the fusion gene was replaced with the $600 \mathrm{bp}$ HindIII-Sal I fragment of YIp33 to construct pTI47 (not shown). This plasmid was used for constructing pTI50 and pTI60 (Fig. 1). A $G A P-S c-l a c Z$ fusion was also constructed and employed as a reference. 


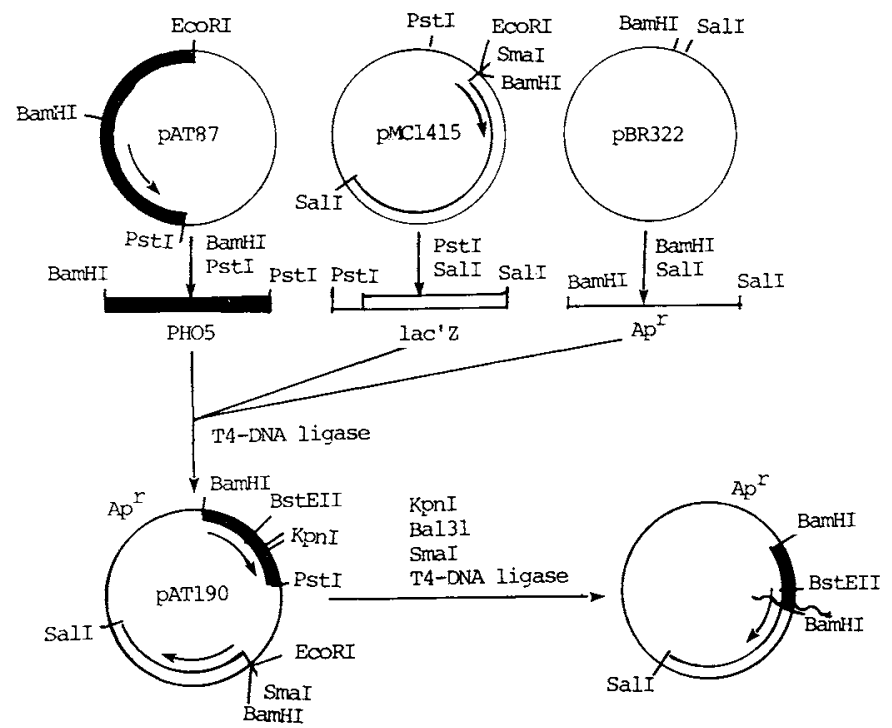

Fig. 2. Construction of the PHO5-lacZ Fusion Gene.

Filled boxes indicate the DNA containing the PHOS gene. Open boxes indicate lac $Z$. Arrows inside the circles indicate the direction of orientation of the gene. The junction between $P H O 5$ and lac $Z$ is shown by a wavy line.

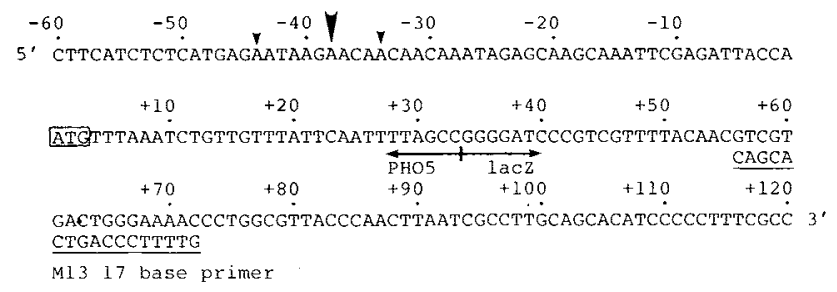

Fig. 3. Nucleotide Sequence Surrounding the PHOS-lac Z Junction.

The 580 bp BamHI fragment was excised from pAT335 DNA and its 5 -termini were labelled with ${ }^{32} \mathrm{P}$ as described. ${ }^{8)}$ The ${ }^{32}$ P-labelled BamHI fragment was then digested with Bst EII and the resulting $200 \mathrm{bp}$ fragment containing the PHO5-lacZ junction, which is shown as a vertical line, was seqeunced by the Maxam-Gilbert method. The $17 \mathrm{mer}$, which was used for the primer extension experiments, is the streach of nucleotides underlined. The vertical arrowheads indicate the transcription start sites determined in the $S$. cerevisiae host. The big one indicates the major initiation site. The initiator ATG of the PHOS protein is boxed.

The $7.6 \mathrm{~kb}$ HindIII-sal I fragment carrying the $G A P-S c-l a c Z$ fusion gene was excised from pGC1 and replaced with the $600 \mathrm{bp}$ HindIIISalI fragment of YIp33 to construct pTI55 (not shown). This plasmid was used for constructing pTI61 and pTI62 (Fig. 1). Plasmids containing the lac $Z$ fusion gene thus constructed had a further insertion at their SalI site of either pSB3 or pSR1 linearized by XhoI digestion (Fig. 1). These plasmids can all propagate in E. coli, S. cerevisiae and $Z$. rouxii.
Production of $\beta$-galactosidase by transformants containing the fusion gene

Each test plasmid was introduced into the indicated host strains of $S$. cerevisiae or $Z$. rouxii by selecting $\mathrm{Leu}^{+}$transformants. Two independent transformants were subjected to the quantitative enzyme assay (Table II). The transformants to be tested were grown in the selective medium and the cells were harvested at the $\log$ phase, and the $\beta$-galactosidase activity was measured. The fraction of cells 
Table II. ExPRESSION OF The GAP-lacZ AND PHO5-lacZ FusIon Genes

\begin{tabular}{|c|c|c|c|c|c|c|}
\hline Plasmid & Fusion gene & Vector & $\operatorname{Host}^{a}$ & $\begin{array}{c}\beta \text {-Galactosidase } \\
\text { units } \\
\text { (A) }\end{array}$ & $\begin{array}{l}\text { Fraction of cells } \\
\text { retaining } \\
\text { plasmid (B) }\end{array}$ & $\mathrm{A} / \mathrm{B}$ \\
\hline \multirow[t]{2}{*}{ pTI48 } & $G A P-Z r-l a c Z$ & pSB3 & ME3 [pSB3] & 643 & 0.652 & 986 \\
\hline & & & & 560 & 0.385 & 1450 \\
\hline \multirow[t]{2}{*}{ pTI49 } & $G A P-Z r-l a c Z$ & pSB3 & ME3 [pSB3] & 863 & 0.495 & 1740 \\
\hline & & & & 1350 & 0.661 & 2060 \\
\hline \multirow[t]{2}{*}{ pTI51 } & $G A P-Z r-l a c Z$ & pSR1 & ME3 & 966 & 0.551 & 1750 \\
\hline & & & & 940 & 0.596 & 1580 \\
\hline \multirow[t]{2}{*}{ pTI52 } & $G A P-Z r-l a c Z$ & pSR 1 & ME3 & 932 & 0.553 & 1690 \\
\hline & & & & 1320 & 0.605 & 2180 \\
\hline \multirow[t]{2}{*}{ pTI61 } & $G A P-S c-l a c Z$ & pSB3 & $\mathrm{ME} 3[\mathrm{pSB} 3]$ & 502 & 0.538 & 933 \\
\hline & & & & 478 & 0.422 & 1130 \\
\hline \multirow[t]{2}{*}{ pTI62 } & $G A P-S c-l a c Z$ & pSR I & ME3 & 455 & 0.589 & 770 \\
\hline & & & & 505 & 0.614 & 822 \\
\hline \multirow[t]{2}{*}{ pTI50 } & PHO5-lacZ & pSB3 & $\mathrm{ME} 3$ [pSB3] & 517 & 0.457 & 1130 \\
\hline & & & & 444 & 0.371 & 1200 \\
\hline \multirow[t]{2}{*}{ pTI60 } & PHO5-lacZ & $\mathrm{pSR} 1$ & ME3 & 463 & 0.660 & 702 \\
\hline & & & & 547 & 0.624 & 877 \\
\hline \multirow[t]{2}{*}{ pTI48 } & $G A P-Z r-l a c Z$ & pSB3 & $\mathrm{K} 12-2 \mathrm{~A}\left[\mathrm{cir}^{0}\right]$ & 71 & 0.068 & 1040 \\
\hline & & & & 65 & 0.033 & 1970 \\
\hline \multirow[t]{2}{*}{ pTI49 } & $G A P-Z r-l a c Z$ & pSB3 & $\mathrm{K} 12-2 \mathrm{~A}\left[\mathrm{cir}^{0}\right]$ & 133 & 0.095 & 1400 \\
\hline & & & & 79.1 & 0.070 & 1130 \\
\hline \multirow[t]{2}{*}{ pTI61 } & $G A P-S c-l a c Z$ & pSB3 & $\mathrm{K} 12-2 \mathrm{~A}\left[\mathrm{cir}^{0}\right]$ & 76.2 & 0.103 & 740 \\
\hline & & & & 82.5 & 0.079 & 1040 \\
\hline
\end{tabular}

a $\quad$ ME3 [pSB3] was used as a host for pSB3-based plasmids. On the other hand, ME3 was used as a host for pSR 1based plasmids, since ME3 contains pSR1 as a resident plasmid. Z. rouxii transformants were grown in SD containing $5 \% \mathrm{NaCl}$. S. cerevisiae transformants were cultivated in a synthetic medium without leucine.

carrying the plasmid was also determined as described under Materials and Methods. pSB3based plasmids carrying the $G A P-Z r-l a c Z$ or $G A P-S c-l a c Z$ genes (pTI48, pTI49 or pTI61) could replicate in a $S$. cerevisiae host, K12$2 \mathrm{~A}\left[\mathrm{cir}^{0}\right]$, but were unstably maintained. This instability is due to the absence of the partitioning mechanism for pSB3 in the heterologous host rather than to their inefficient replication in $S$. cerevisiae. ${ }^{5)}$ Three plasmids showed low but similar stability in the $S$. cerevisiae host. Transformants carrying pTI 48 or pTI49, both of which carry the $G A P-Z r$ lac $Z$ fusion gene, produced higher levels of $\beta$ galactosidase than transformants carrying pTI61, which carries the $G A P-S c-l a c Z$ fusion gene. K12-2A[cir $\left.{ }^{\circ}\right]$ carrying the $2 \mu \mathrm{m}$ DNAbased plasmid with the GAP-Sc-lacZ fusion gene showed an $\mathrm{A} / \mathrm{B}$ value of 1130 , which is similar to that shown by pTI61 in the same host. This result indicates that the promoter of the $G A P-Z r$ gene shows high expression in the $S$. cerevisiae host, as the promoter of the $G A P$ $S c$ gene does. Moreover, expression driven by the $G A P-Z r$ promoter is comparable to or higher than that driven by the $G A P-S c$ promoter in $Z$. rouxii. Since similar levels of $\beta$ galactosidase were produced by the $G A P-S c^{-}$ lac $Z$ gene in the two hosts, we concluded that the $G A P-Z r$ promoter supports the high expression of the lac $Z$ gene in $Z$. rouxii as well as in $S$. cerevisiae. $Z$. rouxii transformants carrying pTI50 or pTI60 produced comparable amounts of $\beta$-galactosidase to those produced by strains carrying the $G A P$-lac $Z$ gene. Constitutive expression of the PHO5-lacZ gene in $Z$. rouxii was unexpected because a positive factor(s) is needed for derepression of the PHO5 promoter in $S$. cerevisiae. ${ }^{10)}$ The PHO5-lac $Z$ fusion gene, when introduced into the $S$. cerevisiae host, only produced $\beta$-galactosidase in low-Pi medium, at a similar level to 
that in the present study (data not shown).

\section{Mapping of the transcriptional start site of the $G A P-Z r$ gene}

In the previous section, it was shown that the $G A P-Z r$ promoter works satisfactorily well in both a homologous and a heterologous host. We tested whether or not the same transcriptional start site of $G A P-Z r$ gene is selected in $S$. cerevisiae and $Z$. rouxii. pTI52, which is a pSR1-based plasmid carrying the $G A P-Z r-l a c Z$ fusion gene, was introducted into the $S$. cerevisiae host and the $Z$. rouxii host. Total RNA was extracted from K122A[pTI52] and ME3[pTI52] cells. RNA $(60 \mu \mathrm{g})$ thus obtained was annealed with $2.7 \mathrm{ng}$ of $5^{\prime}$ ${ }^{32}$ P-labelled 17mer (d(GTTTTCCCAGTCACGAC)), whose $5^{\prime}$ end is located 39 bases downstream from the $G A P-Z r-l a c Z$ junction, and then the primer extension reaction was carried out. Fig. 4 shows that the transcrip-

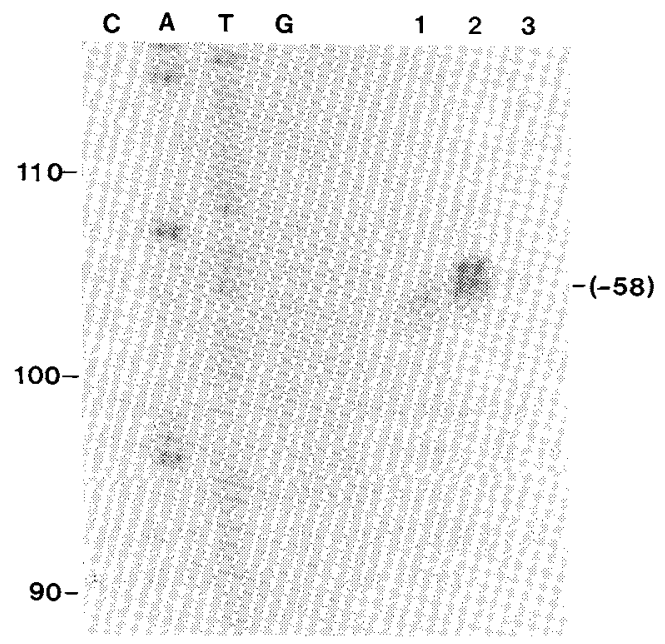

Fig. 4. Determination of the Transcription Initiation Site of the $G A P-Z r$ by Primer Extension.

Total RNA was obtained from K12-2A [ $\mathrm{cir}^{0}$, pTI52] (lane 1), ME3 [pTI52] (lane 2) and ME3 (lane 3). The primer extension reaction was carried out after annealing the RNA with the ${ }^{32} \mathrm{P}$-labelled 17 mer primer as described under Materials and Methods. A known sequence ladder was run in the same gel. The numbers at the left-hand side indicate the lengths and the number at the right-hand side the transcription initiation site used in both $S$. cerevisiae and $Z$. rouxii, which corresponds to $-58 \mathrm{bp}$ upstream of the translation initiation codon of the $G A P-Z r$ gene. tion of $G A P-Z r$ starts at -58 and -59 in $Z$. rouxii and at -58 in $S$. cerevisiae.

\section{Discussion}

An increasing number of yeast genes which can be expressed in a heterologous yeast host have been reported in recent years. ${ }^{11 \sim 13)}$ Each promoter of such genes is a possible donor of a promoter for heterologous expression, however, the promoter function in a heterologous host has not been studied in detail in most cases. In the case of two distantly related yeasts, Schizosaccharomyces pombe and $S$. cerevisiae, the extent of heterologous expression is lower than that of homologous expression and the transcriptional start site of the gene is changed in the heterologous host. ${ }^{14,15}$ ) On the other hand, the $G A P-Z r$ promoter showed high expression in the $S$. cerevisiae host and, moreover, it initiated transcription at the same site(s) in homologous and heterologous hosts.

The constitutive expression of the PHO5 promoter in $Z$. rouxii can be explained in several ways. One obvious explanation is that the PHO5 promoter sequence contains, by chance, a promoter which can be expressed constitutively in $Z$. rouxii. However, it is still possible to assume the presence of a positive factor which can recognize the genuine UAS of the PHO5 gene in $Z$. rouxii. In this context, it should be emphasized that the genomic DNA of $Z$. rouxii contains a sequence which is hybridizable, although weakly, with the $\mathrm{PHO} 4$ gene of $S$. cerevisiae (unpublished result). Further work is necessary to elucidate the mechanism underlying expression of the PHO5 promoter in $Z$. rouxii.

At present, three strong promoters functioning in $Z$. rouxii are available. However, it is still worthwhile obtaining controllable promoters in addition to constitutive ones such as those described in this paper.

Acknowledgments. Part of this work was supported by a Grant-in-Aid for Scientific Research from the Ministry of Education, Science and Culture of Japan. 


\section{References}

1) A. Toh-e, S. Tada and Y. Oshima, J. Bacteriol., 151, 1380 (1982).

2) A. Toh-e, H. Araki, I. Utatsu and Y. Oshima, J. Gen. Microbiol., 130, 2527 (1984). 2a) K. Ushio, H. Tatsumi, H. Araki, A. Toh-e and Y. Oshima, J. Ferment. Technol., 66, 481 (1988).

3) T. Imura, I. Utatsu and A. Toh-e, Agric. Biol. Chem., 51, 1641 (1987).

4) J. P. Holland and M. J. Holland, J. Biol. Chem., 254, 9839 (1979).

5) A. Toh-e and I. Utatsu. Nucl. Acids Res., 13, 4267 (1985).

6) J. Miller, "Experiments in Molecular Genetics," Cold Spring Harbor Laboratory, Cold Spring Harbor, New York, 1972.

7) A. Toh-e and T. Shimauchi, Yeast, 2, 129 (1986).

8) A. Maxam and W. Gilbert, Methods in Enzymol., 65, 499 (1980).
9) S. Hahn, E. T. Hoar and L. Guarente, Proc. Natl. Acad. Sci. U.S.A., 82, 8562 (1985).

10) A. Toh-e, Y. Ueda, S. Kakimoto and Y. Oshima, $J$. Bacteriol., 113, 727 (1973).

11) C. Kohchi and A. Toh-e, Mol. Gen. Genet., 203, 89 (1986).

12) R. Roggenkamp, H. Hansen, M. Eckart, Z. Janowicz and C. P. Hollenberg, Mol. Gen. Genet, 202, 302 (1986).

13) S. Das, E. Kellermann and C. P. Hollenberg, $J$. Bateriol., 158, 1165 (1984).

14) P. R. Russell, Nature, 301, 167 (1983).

15) P. R. Russell, Gene, 40, 125 (1985).

16) L. Clarke and J. Carbon, J. Mol. Biol., 120, 517 (1978).

17) M. M. Casadaban, A. Martinez-Arias, S. K. Shapira and J. Chou, Methods in Enzymol., 100, 293 (1983).

18) D. Botstein, C. Falco, S. Stewart, M. Brennan, S. Scherer, D. Stinchcomb, K. Struhl and R. W. Davis, Gene, 8, 17 (1979). 